\title{
Evaluation of Effluent Discharge from Steel Manufacturing Industries on the Proliferating Environmental Degradation in Nairobi Metropolitan in the Republic of Kenya
}

\author{
Patrick K. Kiongo1, Catherine Njoki Wahome², Peter Muli Muthama ${ }^{3}$, Jeniffer Muhonja ${ }^{3}$, \\ Linah Ngumba ${ }^{3}$, Feisal Hassan ${ }^{3}$, Evans Momanyi ${ }^{4}$ \\ ${ }^{1}$ Kenyatta University Graduate School, Kahawa, Nairobi County, Kenya \\ ${ }^{2}$ Kenya Law Reform Commission, Nairobi County, Kenya \\ ${ }^{3}$ Kenya National Bureau of Statistics, Nairobi County, Kenya \\ ${ }^{4}$ Ministry of Education, Directorate of School Audit Services, Nairobi County, Kenya \\ Email: kiongo2009@gmail.com,wahomecatherine89@gmail.com,pmuthama@knbs.or.ke, jeniffermuhonjacollins@gmail.com, \\ lngumba@knbs.or.ke, fadan@knbs.or.ke, momanyi628@gmail.com
}

How to cite this paper: Kiongo, P. K., Wahome, C. N., Muthama, P. M., Muhonja, J., Ngumba, L., Hassan, F., \& Momanyi, E. (2021). Evaluation of Effluent Discharge from Steel Manufacturing Industries on the Proliferating Environmental Degradation in Nairobi Metropolitan in the Republic of Kenya. Journal of Geoscience and Environment Protection, 9, 198-226.

https://doi.org/10.4236/gep.2021.99011

Received: May 6, 2021

Accepted: September 27, 2021

Published: September 30, 2021

Copyright $\odot 2021$ by author(s) and Scientific Research Publishing Inc. This work is licensed under the Creative Commons Attribution International License (CC BY 4.0)

http://creativecommons.org/licenses/by/4.0/

(c) (i) Open Access

\begin{abstract}
The overall objective of this study was to establish the effects of steel industrial effluent on Nairobi metropolitan water system and its impact to the society. The study sought to identify various types of wastes produced by factories, assess how the waste generated is managed and disposed, examine the effects of effluent discharge on Nairobi River and finally propose mitigation measures. The research adopted a qualitative design and employed a number of methods: direct observations, document reviews to content analysis of the past studies, which in the end generated invaluable data. The study revealed that there are four categories of waste generated: solid waste, liquid waste, footbath chemicals as well as thermal wastes. It was also found that waste management in place was not effective enough leading to water and soil pollution. Other causes of pollution were found out to emanate from gasses contamination to the air and chemicals used during steel processing. The findings will inform the community of the harmful effects of untreated water and how it impacts on their health and productivity. It will also help the stakeholders in the environmental conservation to articulate issues of policy and influence agenda setting in the national and sub-national levels.
\end{abstract}

\section{Keywords}

Effluent Emissions, Environmental Assessment, Environmental Audits, Environmental Degradation, Environmental Standards, Industrial Effluents, 
Pollution, Solid Waste

\section{Introduction}

The rapid growth of steel manufacturing industries has led to the increased effluent emissions which have sparked public health and environmental concerns. Effluent emissions have caused environmental pollution in various forms which have become a threat to the wellbeing of humanity and to the prosperity of nations. Exposure to the pollutants at sufficiently high concentrations can cause a variety of health problems (Dara, 2002). According to Hassan and Amadi (2013) the intensity of environmental pollutants from industrial wastes has attracted the attention of scientific and administrative authorities all over the world. A pollutant is a substance that occurs in the environment as a result of anthropogenic activities and which has a harmful effect on the environment (Moriarity, 1990). Pollution is a major environmental concern in the world over owing to its adverse effects on the living organism.

Discharge ideals are key management tools that ensure the stability of the receiving systems. The major sources of industrial effluents are associated with steel processing industries and chemical manufacturing. Effluents like oil and grease could come from a variety of sources like crude oil production, oil refiners, petroleum products, metal processing, lubricants, car washings and restaurants (Lan, Gang, \& Jinbao, 2009). The nature of the effluents depends on the types of raw materials used in the industries and the efficiency of the industrial processes. The analysis of the effluents is important in environmental monitoring and the potential health effects of the by-products (Sanchez \& Bosch, 2005).

As the Nations develop their industrial activities, production and use of chemicals rise in response to the standards of living and consequent increase in life expectancy (Adepetu \& Ezianshi, 1998). It is therefore important to treat the industrial affluent before their discharge in order to reduce environmental degradation and have sustainable living standards. The steel manufacturing and related productions in Kenya are, to large extent dominated by a very bulk importation of chemicals for application in various manufacturing processes. The manufacturing industries located in Nairobi's industrial area emit their effluents into the Nairobi River. It has been reported that industries discharge untreated effluents into public sewer which eventually enters the river (Omoto, 2006). The pollution observed in the Nairobi River had been attributed to emission of industrial effluents into the environment by manufacturing industries within the neighbourhood. Such emissions have raised great concern from environmentalists, the public as well as the regulators in regard to the toxicological effects on supply of clean domestic water as well as the wellbeing of aquatic organisms whose natural habitat has been destroyed by the effluents. The water pollution 
ensues when a pollutant is released into water bodies without undergoing proper treatment. Some of the pollutants are also deposited on the land thereby rendering agriculture harmful.

In view of the potential health problems and the negative environmental impact has arisen from such effluents, the research will focus on evaluating the effects of effluent discharge from steel manufacturing industry on the environment in Nairobi metropolitan, Kenya.

Before the enactment of Environmental Management and Co-ordination Act (EMCA) in 1999, Kenya's environmental laws had been sectoral. Therefore, enforcement faced serious difficulties due to multimedia transfer of pollution from one medium to another, for example when pollutants in dumped, solid waste find their way into ground water. EMCA is a basic framework law that deals with pollution control among other environmental issues. One of the principles of environmental pollution control is the establishment of environmental standards.

In the case of water pollution, the standards include effluent discharge and water quality standards for water bodies such as rivers and lakes. Attempts have been made to develop Kenya standards for effluent discharge but so far, no standards have been gazetted into law. Proposals are taken as guidelines and they lack effective enforcement capabilities. One of the reasons facing standard development has been lack of evaluating the effects of effluent discharge from steel manufacturing industry on the environment in Nairobi metropolitan.

Industrialization and rapid population growth have created major environmental problems in Nairobi. Pollution of rivers passing through the region has been of great concern to both the residents and authorities. Nairobi River is one of the rivers that pass through the city for a distance of $28 \mathrm{~km}, 10 \mathrm{~km}$ of which is through the main industrial area. Before passing through the industrial area, the river passes through one of the largest slums in Africa, that is, the Kibera Slums, which discharge its raw domestic and commercial waste into the river. This has resulted in the entire coverage of Nairobi Dam with water hyacinth. Adjacent to the industrial area are other slums that pollute in a similar manner.

The major objectives of the study include;

1) To assess the effectiveness of waste management and disposal mechanisms practiced by steel processing industries in Nairobi.

2) To examine the effects of steel processing industries effluent discharge into Nairobi River on the surrounding communities.

3) To propose the mitigation measures to help curb the impacts of the steel processing effluent discharged into the Nairobi River.

Water pollution is as a result of human activities that makes the water dangerous to human beings, unfit for industrial use and adversely affects the aquatic fauna and flora among others. Water pollution is associated with human population explosion and industrialization. The main sources of water pollution are industrial discharge, sewage, agricultural waste, fertilizers, seepage from waste 
sites, decaying plant life, road, railway and sea accidents involving large oil carriers (Kinchella \& Hyland, 1993).

The city of Nairobi has experienced rapid industrialization and growth in population during the last 100 years (Okoth \& Otieno, 2001). This rapid growth has not been matched by development of infrastructure to deal with waste disposal. As a result, problems have arisen with regard to industrial waste disposal leading to pollution of the water resources. Sources of pollution of the Nairobi River include industrial effluent, effluent from petrol stations and motor vehicle garages, surface run off, from factories and other business premises, raw sewage from broken or overloaded sewers as well as raw sewage from informal settlements (Ndwaru, 1994; Otieno, 1995; Okoth \& Otieno, 2001).

Metals enter the aquatic ecosystem primarily through the indiscreet disposal of chemical and metal wastes from agricultural, industrial and mining activities. Being non-biodegradable these metals accumulate in the tissues and organs of living aquatic organisms thereby affecting the normal processes of the body. Some of these metals, such as mercury, are very toxic to human beings. Essential metals are required in micro amounts in living systems although at higher concentrations, the metal ions are toxic to the ecosystem.

\subsection{Justification and Significance of the Study}

Industrialization is beneficial to mankind as it creates employment opportunities. Through industries, employment opportunities are created which in turn generate income which helps to improve the living standards of the community. Despite the importance, industrialization has adverse impacts on the natural environment through pollution. Negative externalities associated with poorly managed industrial effluence pose threat to the health of both aquatic organisms but also and terrestrial animals and human life that depend on the water.

However, with proper interventions like management of the industrial effluent including treatment at source such negative externalities can be averted. This can be through sound policies and legislative frameworks, proper enforcement, enhancement of the institutional capacities and creation of awareness on environmental management techniques by the government. Besides, government interventions, support and involvement of non-state actors including $\mathrm{CBOs}$ and NGOs in environmental governance, a balance between sustainable industrial production and environmental management can be realized.

This study will be of significance to the community living within the Nairobi metropolitan in various ways. First, the study will help them understand how the use of untreated water from river has been affecting their health and livelihoods. The study will help the communities identify best water treatment mechanisms that will help protect them from possible effects of water and environmental contamination.

To the policy makers and planners in the health sector, the research findings will help them have a clear foresight on priorities and options that will protect 
the surrounding communities from effects emanating from poor management of industrial effluent. By incorporating them in their planning and policy making processes, it will eventually improve the livelihood of the citizens residing along the Nairobi metropolitan areas. Findings from this study will be used by various non-state actors and environmental stakeholders such as the National Environment Management Authority and interested donors by pointing out possible areas of interventions and collaborations to enhance quality on environmental protection and livelihoods. Besides contributing to the general body of knowledge for the environmental conservation stakeholders, the findings will also be of value to other researchers as they carry out more studies in endeavour to develop the sector.

\subsection{Scope and Limitations of the Study}

The study used Nairobi River as a case study to establish the effects of industrial effluent on Nairobi metropolitan that supports livelihoods of the surrounding communities. The study will bias its focus to pollution resulting from organic industrial waste waters associated with causing the common water borne diseases including lead poisoning, mercury poisoning as reported by the various newspaper reviews, articles and case law.

The study is constrained by limited time and financial resources that would otherwise have allowed covering the entire population within the study area. The study was limited to lack of comprehensive primary data especially on how the residents have been seeking medical attention from the effluents. In addition, due to time and cost limitations, the study will not be carrying out laboratory analysis of the water contents and ascertain the levels and nature of contamination of the Nairobi River water.

The data collection will be constrained to secondary data collection articles from desktop review of previous studies conducted on the Nairobi River and data analysis conducted by various state and non-state actors.

This will have shed more light on how the industrial effluents such as iron, chemicals, fertilizer and other oil related effluents pollute the environment and possibly get their way to the river through erosion or direct discharge as well as assessing their related possible threats to human health.

\section{Theoretical Framework}

\subsection{Theory of Environmental Degradation and Ecological Reform}

Sociological engagement with material bases of social life has a long but intermittent and sometimes forgot the founding scholars. The emergence of the modern environmental movement in the 1960s and events like the first earths day in 1970, followed soon after by the postulation of material limit to growth, whilst generating significant sociological interest, also revealed the inadequacy of then dominant forms of sociological enquiry. This also includes recent development and theories of environmental degradation and ecology reforms, Catton 
and Dunlap $(1978,1980)$. This study links this theory to environmental degradation and sociological reforms in the study area, Nairobi County and environs, Kenya.

\subsection{Theory of Environmental Protection}

The modern largely academic and urban initiated concern with environmental protection of landscapes, species, watersheds, biodiversity, ecosystem-services etc. are framed by a language suggesting that the main concern is the protection and preservation of precarious resources of common interests for mankind. Thus the values deserving the attention of environmental protection seem to be very different from the concerns shaping the evolution of traditional commons. The control of access to and extraction of resources seen as limited but essential for the survival of local communities.

In designing new institutions for managing protected areas, an understanding of traditional commons and how the new values to be protected are different from and interact with the old values will be important to achieve sustainability of resource use within the protected areas, Erling Berge (2003). This study focuses on the environmental protection linking with the theory.

\subsection{Theory of Environmental Regulation}

The overexploitation of commonly-held resources is typically analysed as an instance of market failure that calls for legislation to internalize the social costs that private activities impose on the environment. In the tragedy of the commons, Garrett Hardin (1968) points out that there are two solutions to the tragedy: privatize the resource or restrict access to it. Environmental legislation is a means of restricting access to the commons. Evolutionary development of common law is a means of privatizing the commons. These represent alternative methods of environmental regulation.

Public policy analysis requires a comparative assessment of the efficiency of these methods for resolving any particular environmental problem. In many cases, if not most cases such an assessment will show common law regulation to be superior to environmental legislation, John Hasnas (2009). This study links environmental regulation to the case study.

\subsection{Theory of Environmental Policy}

Natural capital theorists seek to emphasize the overriding importance of the environment to all other parts of life while environmental economists are situated in the market theory and place natural capital alongside other forms of capital in assigning costs and benefits. Through his analysis, Edward Cheng (2011) shows that two distinct types of policies are drawn upon each of these theories; One which emphasizes restricting mans impact on the environment because of limited resources and unknown effects and the other which seeks to use the market to compensate environmental costs but which also seeks to develop ways of con- 
tinuing human growth and development while reducing environmental impacts through technology.

\subsection{Theory of Environmental Sustainability}

Simultaneously the scarcity of the resource triggers a process of technological research to find new technological solutions for the attainment of the same production targets though using different materials and methodology.

Among the scholars who deepen and pose critics to marginalists approach (Georgescu, 2013) suggests that economic science should take greater account of the laws of nature by demonstrating real irreversibility of materials and energy implications of production processes. He rejects the depiction of the economic process as separate from the environment in which it takes place, suggesting the physical connection with the terrestrial system subjected to gradual increase of entropy.

Environmental damage will most likely produce negative effects on third parties that is, welfare losses not compensated, an economic and social assessment widespread and that the needs of each person on earth are met, and each has equal opportunity to realize their human potential, Virginia \& Natalia (2013).

\section{Conceptual Framework}

From Figure 1, the major pollutant emanates from the industries, the populous human settlements, farm chemicals and untreated sewerage system. This affects the water quality along the river thereby contributing to the deteriorating health both human and aquatics.

The global atmospheric watch (GAW) programme and Millespheric transport highlighted deposition of potentially harmful substances over terrestrial, fresh and marine ecosystems and the natural cycling of chemical elements in the global atmosphere. This programme provides data and information on the chemical composition and related physical characteristics of the atmosphere or ocean or biosphere and anthropogenic impacts theorem (Scudine, 1998). The study shows the effects of discharge of understanding the relationship between changing atmospheric composition, changes of global and regional climates, and steel manufacturing industry in the case study area; Nairobi metropolitan, Kenya.

Figure 2 represents a significant addition to the spectrum of environmental health hazards faced by humankind. The global scale makes for unfamiliarity, although most of its health impacts comprise increases or decreases in familiar effects of climatic variation on human biology and health. Traditional environmental health concerns long have been focused on toxicological or microbiological risks to health from local environmental exposures. However, in the early years of the twenty-first century, as the burgeoning human impact on the environment continues to alter the planet's geological, biological and ecological systems, a range of larger-scale environmental hazards to human health has 


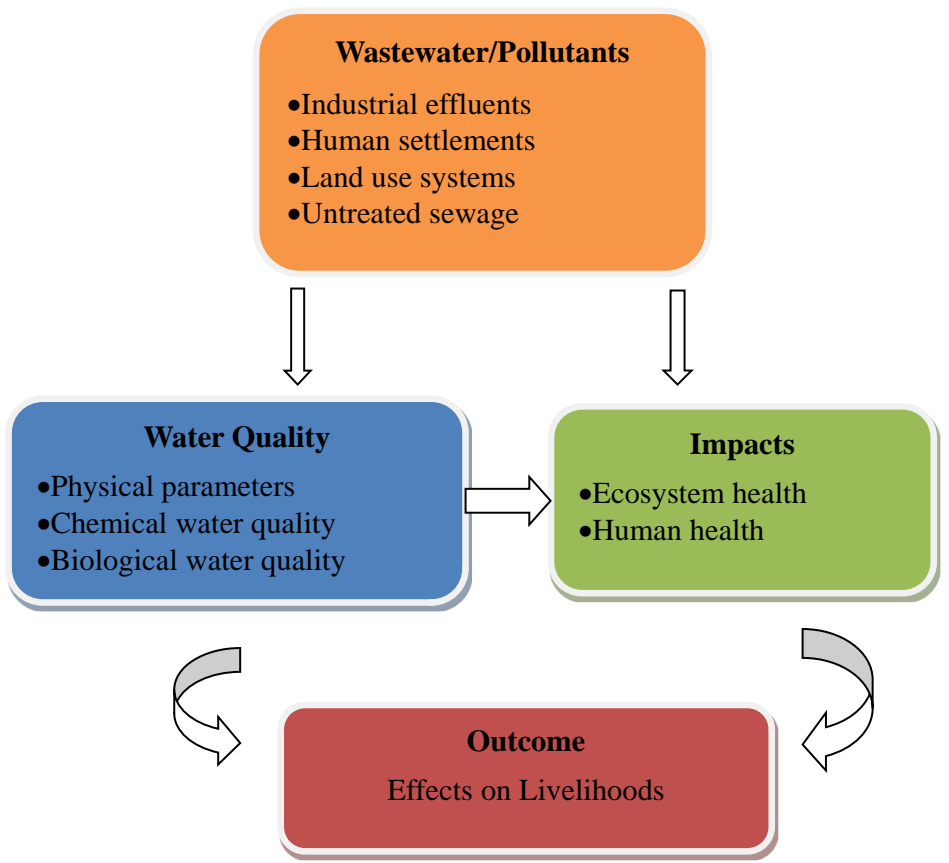

Figure 1. Conceptual Framework. Source: Author.

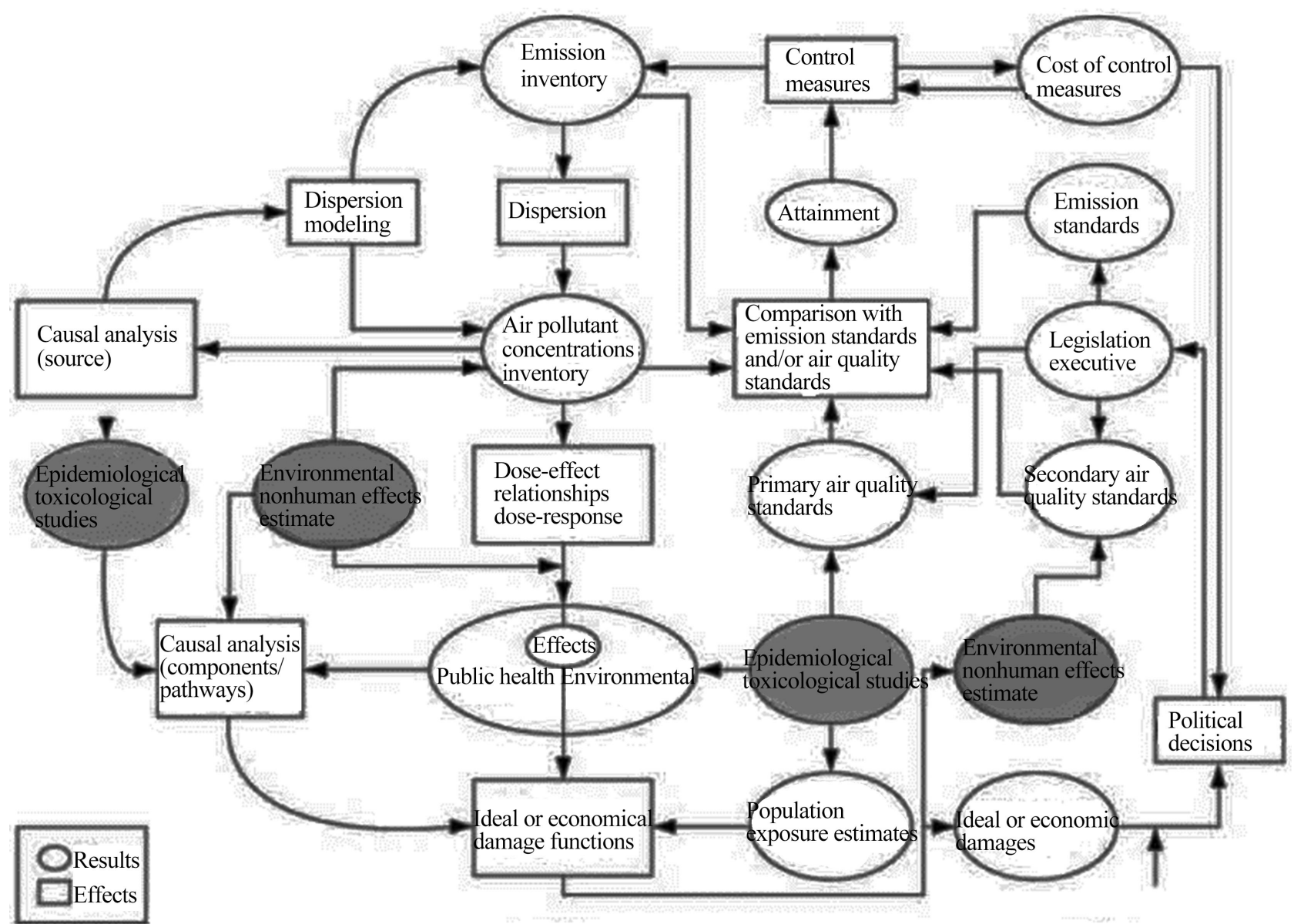

Figure 2. Global Environmental monitoring system pollution management. (Source: Encyclopaedia of occupational Health and safety 4th Edition-ILO Encyclopaedia.) 
emerged. In addition to global climate change, these include: the health risks posed by stratospheric ozone depletion; loss of biodiversity; stresses on terrestrial and ocean food-producing systems; changes in hydrological systems and the supplies of freshwater; and the global dissemination of persistent organic pollutants, McMichael et al. (2007).

\subsection{Metal Status of Nairobi River Waters and Their Bioaccumulation in Labeo Cylindricus}

Budambula \& Mwachiro (2006) in her study focuses on the analysis of metals in water and from Nairobi River. Water from Kikuyu Kawangware, Chiromo Eastleigh, Njiru and fourteen Falls along the Nairobi River was analysed for the presence of metal levels in water were below the critical limit of The World Health Organization and Kenya Bureau of standards except for Lead, Chromium, Iron and Manganese. Except for Iron, Sodium and Potassium, there was no significant difference in the concentration of metals at different sites.

This study also analysed metal levels in fish organs and tissues of fish caught from downstream (Fourteen Falls). Although metal levels were within normal levels in the water at Fourteen Falls, Mercury, Copper, Lead and Iron recorded higher than accepted levels in some fish organs. This calls for caution in the consumption of fish from Fourteen Falls.

\subsection{Levels of Heavy Metals in Waste Water and Soil Samples from Open Drainage Channels in Nairobi, Kenya: Community Health Implications}

In their study, Kinuthia, Ngure, Beti, Lugalia, Wangila and Kamau (2020), establishes the concentration of Mercury, Lead, Chromium, Cadmium and Nickel in samples of waste water channels in selected sites in Nairobi's industrial area, Kenya. There are many informal urban settlements/villages that neighbour Nairobi industrial area and some of the waste water channels drain into a tributary of Nairobi River which flows across these villages.

Clogged waste water channels enhance overflow of the waste water into the surrounding areas through surface runoff when it rains.

Therefore, the current study aims to highlight the potential health risk that may ensure when humans, livestock and crops become directly or indirectly exposed to the steel contaminated waste water and soil from the open channels in the study area. It envisaged that the results obtained from the study will inform and justify on the need to adopt good waste water management including prioritizing on effective waste water treatment and reuse in Kenyan major urban areas.

Previous studies have shown that the degree of treatment determines the applicability of the reclaimed wastewater water.

\subsection{Effects of Nairobi Industrial Areas Effluents on Levels of Ngong River Pollution}

In their study, Njenga, Oyake and Kamau (2019), focuses on the level of pollu- 
tion in industrial effluents discharged into the section of Ngong River flowing and how this pollution affected the river pollution levels.

Metal working, metal finishing and paint manufacturing activities especially between Enterprise road and outer Ring Road bridges contributed to levels of metal pollution in both the effluents and river samples.

Ngong River was found to be heavily polluted with respect to organic pollution. High levels of metal made it unsuitable as a source of drinking water within the study area.

To improve the quality of Ngong River water, Nairobi city County, NEMA and individual manufacturing firms all have a role to play.

\subsection{Heavy Metal Pollution in Sediments, Water and Flora along Chania River}

Mwangi (1988), investigated the effects of agricultural oxygen demand domestic and industrial on the quality of Thika-Chania River System. In the study parameters such as suspended solids, the biological oxygen demand and heavy metals were analysed. For all these parameters the levels never exceeded the, recommended value except chlorides.

The levels of all heavy metals analysed did not exceed $2.6 \mathrm{ppm}$. Their study recommended that the specific points of discharge of these elements be identified and implemented.

Concerns have been raised in the recent past concerning pollution of the Thika River. In 2015, the Gatuanyanga residents in Thika East Sub-County complained about the health effects due to emissions from the nearby Asphalt factory which borders the Chania River, a confluent of the Thika River downstream. Consequently, the factory eventually closed down following public complaints, Musembi et al. (2015).

\subsection{Regulatory Frameworks for Environmental Management}

Regulatory framework has been established by the National Environmental Management Authority-NEMA in Kenya to control waste disposal and minimize environmental pollution. For example, solid waste management in Kenya is managed by the Public Health Act 1986, The Environmental Management Regulations, 2006 and the Environmental Management and coordination Act (EMCA), 1999 (National Council for Law Reporting, 1986). These Acts provides for proper waste management such as incineration, re-use, dumping, recycling and landfills. For example, section 87 of EMCA outlaws indiscriminate waste disposal methods that can pollute the environment or cause sickness to a person who engages in activities that produce waste is required to establish necessary measures to minimize waste through recycling, reclamation and treatment. The EMCA also provides water quality regulations which minimize pollution in aquatic environments. For instance, it prohibits the discharge of any effluent from industry sewage treatment works or other point sources without a valid ef- 
fluent discharge licence (National Council for Law Reporting, 1999). The EMCA 2015, CAP 387 provides for regulations and guidelines for environmental assessment and environmental audits in principle to ensure that all project activities have minimal negative impact to the environment (National Council for Law Reporting, 2015).

\subsection{Statistical Data Analysis for Assessment of Heavy Metal Pollution Levels}

In the study, the concentration results obtained was subjected to analysis. In this study the degree of contamination and heavy metal enrichment in sediment samples were assessed through pollution factors such as the enrichment factors, geo-accumulation indices, contamination factors and pollution load indices.

From the previous researchers, there is little information on steel waste management. This research aims on adding or increase body knowledge that will help on conservation of rivers and environment (pollution from steel manufacturers). The previous researchers concentrated on heavy metals like (mercury, lead, chromium and iron + carbon). This research aims at evaluating the effects of effluent discharge from steel manufacturing industry on the environment. It aims at assessing the effectiveness of waste management and disposal mechanism, examine the effects in Nairobi metropolitan and propose mitigation measures to help curb the impacts of steel effluent discharge into the Nairobi metropolitan rivers.

\section{Research Design}

This study broadly focused on industrial effluent in the Nairobi metropolitan, which was identified because of its high concentration of industries hence reasonably anticipated to have the highest amount of industrial discharge. Steel manufacturing discharge was selected for this study because of the inadequate research that had been conducted on the subject matter in the past.

The research adopted a qualitative study. The descriptive research approach was designed to realize the outlined objectives. The observation of environmental features was specifically intended to provide insight on the extent of effluent waste emissions by manufacturing industries in Nairobi metropolitan. The environmental phenomena of study were evaluated descriptively to comprehend the major cause-effect of affluent discharge from steel manufacturing. The purpose of this was to get more in-depth assessment, and thus more detailed data, on the extent of effluent waste emissions to natural rivers by industries in Nairobi metropolitan.

The other methodological approach was a review of available publications and papers, also known as desk review, on the subject, in a bid to evaluate the extent of effluent waste emissions by industries in Nairobi metropolitan. The premise here was that, in order to evaluate and understand the efficacy of effluent waste management, there has to be knowledge of the extent of emissions of the waste. 


\subsection{Site of Study}

The study was conducted in Nairobi metropolitan, Kenya. This is where most of the steel manufacturing industries are located. Most of these industries emit their by-products to nearby rivers thereby contaminating the water and the environment.

The study focused on steel manufacturing industrial discharge to the rivers in the Nairobi city and surrounding parts of Machakos, Kiambu and Kajiado which were selected because of its high concentration of steel manufacturing industries and thus reasonably expected to have the highest amount of industrial effluent discharge.

\subsection{Target Population, Sample Size and Sampling Procedures}

According to Mugenda \& Mugenda (2003), a population is an entire group of individuals, events or objects, having common observable characteristics. In this study the population included the Nairobi, Chania, Ngong and Athi rivers which are within the Nairobi metropolitan area. It involved the residence areas in Kawangware, Chiromo, Eastleigh, Njiru, Fourteen falls, Gatuanyaga, Athiriver, Ngong and Industrial areas which are urban and semi-urban areas located along the axis of study.

In specific terms, however, the study came down to the industrial areas of Nairobi, as pointed out in the study design, that have residential areas near industries. This intended singling-out settlement areas which includes Pipeline settlement, Mukuru Kayaba, South B, and Baba Dogo areas within Nairobi. These samples have been identified purposively since the areas provide the runway to Nairobi river system and have also been reported to experience affluent flooding during rainy seasons. Therefore, the area can be said to bear the effect of environmental dilapidation thus making it an ideal area of study.

\subsection{Data Collection Techniques and Analysis}

The study employed a number of methods: direct observations, document reviews to content analysis of the past studies, which in the end generated invaluable qualitative and quantitative data. According to Creswell (2003) the use of more than one method to investigate the same research problem strengthens research findings through the combination of information sources and analytical approaches. Mixed method approach helps to overcome any bias, which is inherent within a single method approach, adds value to the theoretical debate and also complements the limitation of one method with the other's strength (Creswell, 2003: p. 210).

Currently available documents and reports on effluent waste were analyzed and reviewed. This included reports and publications of the Ministry of Environment, UNEP, Nairobi City Council, NEMA-Kenya, World Bank and Environmental Impact Assessment reports, on effluent waste in the country in general and in particular Nairobi metropolitan. These reports were deemed relevant, 
as they would help shed light on effluent waste statistics, the challenges of management and possible solutions.

The research employed qualitative data analysis techniques, since, first, the structure and nature of this research was found to favor this kind of methodology since qualitative data was generated. Secondly, qualitative methods are usually considered strong on validity. The logic here was that the method would thus improve the quality of the research.

\section{The Regulatory Environment}

There are a number of pieces of legislation scattered around the Kenyan statute books and the by-laws of the County of Nairobi that are directed at improving environmental sanitation, although only a few of this attempt to directly address the question of steel effluent waste management. But there are other better-known pieces of legislation like the Environment Management Coordination Act (EMCA), that have direct influence on the management of effluent waste in the country in general and in the city of Nairobi in particular. The newly promulgated constitution has elaborate provisions on land, environment and water and this should go a long way in boosting the other available provisions like EMCA, which will themselves need to be amended in order to align them with the new constitution (Okello et al., 2009).

Kenya's EMCA 1999, is however just a general framework law that is supposed to provide general guidelines for environmental conservation and does not specifically seek to address the question of wastewater management. Instead, it provides for the establishment of an appropriate legal and institutional framework for the management of the environment and related matters. The Act attempted, at the time of its formulation in 1999, to improve the legal and administrative co-ordination of the many initiatives across various sectors with the aim of improving the capacity of the government to manage the environment. There are other pieces of legislations adopted since the enactment of EMCA that have a direct bearing on the management of waste effluent from industries in Kenya (Kazungu, 2010).

\section{Waste Management Regulations}

Along with the water quality regulations, the Minister for Environment and Natural Resources also published waste management regulations in 2006. The purpose of the Waste Management Regulations was to streamline the handling, transportation and disposal of various types of waste. And like water quality regulations, waste management regulations were formulated with the aim of protecting human health and the environment. The regulations emphasize waste minimization, cleaner production and segregation of waste at source. It was founded on the understanding that currently, different types of waste including steel effluent are dumped haphazardly, posing serious environmental and health concerns. 
The regulations have classified various types of waste and recommended appropriate disposal methods for each waste type. Under these regulations, NEMA-Kenya licenses transporters, incinerators, landfills, composers, recyclers and transfer stations. Facilities to be licensed include local authorities, transporters and handlers of various types of waste. The licensing employs a risk-based approach by concentrating on facilities considered to pose a high risk to the environment. The Waste Management Regulations also provide an opportunity for investment in various aspects of waste management (Monyoncho, 2013). The regulations have certain specific yet very stringent provisions. Those emitting effluent discharges to the environment are, for example, required to state the types of waste that are supposed to be disposed of at a treatment plant. They are supposed to state whether the waste is hazardous, domestic, industrial or biomedical. They are also supposed to state the quantity of waste they dispose of per annum, besides indicating the type of treatment and facility to be used at the treatment plant.

\section{General Observations Inferred from the Study}

This study finds that contrary to the general perception, the legal regime on waste effluent from steel industries and the fact that the law is not being followed to the letter could be attributed to the weaknesses of the regulatory authorities whose duty is to enforce the law. This is not to deny the fact there could loopholes or weaknesses in the existing law. The magnitude of the weaknesses in the law and how this contributes to the poor waste management practices can only be determined if and when the existing law will be fully implemented, including when the available oversight mechanisms have been fully utilized.

\section{Oversight Authorities}

Because of the cross-cutting nature of the issues of environmental conservation in general and effluent waste in particular, the jurisdiction and even the responsibility for the enforcement of the law and regulations touching on the same would ordinarily fall onto the laps of a number of government departments and ministries.

\subsection{Relevant Ministries, Departments and County Government}

The question of steel effluent waste management should naturally be of concern to the Ministry of Environment and Natural Resources. The ministry should generally be well informed, if not deeply involved, in how such waste gets managed, treated and discharged, in the country. In any case, by virtue of its wide health hazards, the Ministry of Health cannot ignore the matter, as it has the capacity to lead to an increase in the cases of water borne diseases and thus have a direct impact on the health budgets. Further, the fact that waste effluents ordinarily impact on the quality of water therefore means the Ministry of Water cannot ignore its significance, as indeed has been the case in other countries 
around the world. Ministries of health are directly concerned with questions of water quality and management of effluent wastes.

The Ministry of Education should be concerned with the manner of management of industrial effluent should it pose a risk to the school system, while the Ministry of Agriculture should have direct interest since the manner of management of industrial effluent has the potential to impact on land use systems or practices and thus the agricultural output (Ojanji, 2014). The office of the Attorney General and the Ministry of Justice should be directly concerned with the question of industrial steel effluent discharge management in the country, whether for the simple reason that the law exists and is not being enforced or that there is actually no comprehensive law to address some of the challenges in the sector.

\subsection{Regulators Failing to Take Responsibility}

The reality found in the course of this study should be of great concern to the environment sector. The Ministry of Water, for instance, has maintained that issues of waste effluent do not fall within the Ministry's mandate. The Ministry has maintained that it only deals with matters of policy and had nothing to do with the specific enforcement of regulations on water. The Ministry of Water does not have any data on waste discharge from industries in Nairobi that would pollute water sources, which would mean that the Ministry would find it difficult to even start to respond to such challenges.

The Water Services Regulatory Board deals with water sources and water service provision (supply) and not waste discharges from industries, a matter the board preferred to refer to the Ministry of Environment. Officials at the Ministry of Health, both Public Health Ministry and the Medical Services Ministry, argued that the ministry is supposed only to provide medical services, facilities, drugs, policies and oversight functions to the sector and does not therefore concern itself with effluent discharges from industries, equally pointing out that such matters are the function of the Ministry of Environment (Muthaka et al., 2004).

The Ministry of Health therefore equally lacks any data on industrial discharges, even the toxic ones that would course serious health hazards, or even the general list of industries that would emit effluents into the environment. Such a list was to be found with the Ministry of Trade, which only keeps it as a list of businesses or investors in the country, with little attempt at looking at the environmental dimensions.

The Ministry of Environment deals with the formulation of policies and laws as well as offering oversight services to the sector. The functions of the enforcement of laws on environment, and thus determining who was flouting which law, fall within the purview of the National Environment Management Authority. The management of industrial waste discharge, including data of which industry discharges what effluent to the environment and what level of treatment the effluent is accorded before discharge, is the mandate of NEMA-Kenya and 
the Ministry does not therefore keep such data. The Nairobi City County delegates its waste water (meaning sewerage functions) to the now semi-autonomous Nairobi Water and Sewerage Company and deals only with sewage that goes through its sewerage systems and does not deal with all cases of industrial discharge.

Indeed, and as noted above, by law NEMA-Kenya is supposed to keep such data and also enforce the law by prosecuting and meting out direct minor punishment to offenders, as prescribed by the law. But NEMA-Kenya website indicates that only a handful of industries have been filling in the mandatory quarterly records as required by law. NEMA-Kenya has argued that this process is voluntary and only those industries that offer to do it should do it. Majority of the industries in Nairobi, and presumably in other parts of the country, do not file the quarterly records (Wangombe, 2013).

The deficiencies in the management of industrial effluent discharge are therefore directly attributable to the failures of the law enforcement agencies, including NEMA-Kenya. But other sector players have attributed the failure of the laws and regulations for waste management in Nairobi to a number of handicaps, especially on provisions and sanctions to deal with those who flout them, weakness of the related agencies and the inability or unwillingness of officials to enforce such laws (Kazungu, 2010).

\section{Quantities of Industrial Effluents in Nairobi}

The study found that, although Nairobi has two wastewater treatment plants, the county authorities say they do not compute quantities of discharge either per sector or overall. The Dandora/Ruai sterilization ponds treat both industrial effluents and domestic sewage. It has a design capacity of 80,000 cubic meters per day and constitutes the largest pond system in Africa. The Kariobangi wastewater treatment plant has a capacity of 32,000 cubic meters per day and uses the trickling filter technology. This makes a total of 112,000 cubic meters per day of effluents from both plants that are ultimately discharged into the Nairobi River. However, since Nairobi county authorities estimate that at least 6 percent of the effluents are from steel industries, the total industrial discharge per day can be computed as per the table below. Of all the effluents from industries, an estimated 60 percent is from the steel processing and general industries while the rest is from Fats, Oils and Grease (FOG) type of industries, such as hotels and petrol stations.

Table 1 shows the volumes of industrial discharge for the 600 industries that discharge their effluents into the Nairobi City Water and Sewerage Company System. But, according to NCWSC website, only 6 percent of this waste comes from the 600 industries that discharge into the Nairobi City Water and Sewerage Company system. This means that, 600 industries that treat their effluent through the NCWSC system discharge a total of 2,419,200 cubic meters of waste into the Nairobi City Water and Sewerage Company system. 
Table 1. Estimated volumes of industrial effluents in nairobi.

\begin{tabular}{lcccc}
\hline No. & Category & $\begin{array}{c}\text { Emissions per day } \\
\text { in Cubic Meters }\end{array}$ & $\begin{array}{c}\text { Emissions per month } \\
\text { in Cubic meters }\end{array}$ & $\begin{array}{c}\text { Emissions per Year } \\
\text { in Cubic Meters }\end{array}$ \\
\hline 1. & Dandora/Ruai Plant & 80,000 & $2,400,000$ & $28,800,000$ \\
2. & Kariobangi Plant & 32,000 & 960,000 & $11,520,000$ \\
3. $\begin{array}{c}\text { Industrial Discharge } \\
\text { for 600 industries }\end{array}$ & 6720 & 201,600 & $2,419,200$ \\
\hline
\end{tabular}

Source: Nairobi City Water and Sewerage Company Report 2019.

\section{Data on the Total Number of Industries in Nairobi}

The study found that, by July 2016, data from Kenya National Bureau of Statistics (KNBS), Economic Survey Report on Manufacturing Industries, Nairobi was showing that Kenya had a total 4861 industries, all classified by KBS as manufacturing industries. At least 54 percent or a total of 2625 of these industries are found in Nairobi. More than 60 percent of all the industries in Kenya are manufacturing food or related products. It is however difficult to assess the concentration of industries within Nairobi, as the data does not contain specific information about the location of each industry within Nairobi. The study further found that this data varies from that of the Nairobi City Water and Sewerage Company (NCWSC), which has records of just 1519 industries in Nairobi. The difference is likely due to either variation in the way the two organizations categorize entities as industries or it could be more of a reflection of the lack of rigor on data management by the Nairobi City Water and Sewerage Company.

The study further established that, of the 1519 entities NCWSC has listed as industries, just 600 industries discharge their waste effluent into the sewerage system of the NCWSC, which first treats the discharge at its two treatment plants in Ruai and Kariobangi before releasing into the environment. The licensed industries are required to file during every quarter analyzed samples showing the quality of discharges.

Going by data the researchers acquired from Kenya Bureau of Standards, this means that at least 2025 industries in Nairobi do not discharge their waste effluent into the NCWSC system for treatment. The gap can be attributed to the lack of cooperation from industries and, two, the fact that NCWSC lacks necessary powers, as per the law, that would either compel industries to comply or be penalized, and that such powers are vested in NEMA. NEMA website does not share data of the industries that are compliant with waste management requirements, only describing the data as scanty (meaning that just a few industries comply).

Table 2 shows the distribution of industries with effluents emissions to the Nairobi River and from the analysis only 600 out of the existing 2625 industries in Nairobi metropolitan city that channel their effluent to the NCWSC treatment system provided in the city. However, there are further 1519 which are licensed to use the NCWSC System but fail to empty their emission for treatment and disposal in addition to further 2025 of which do not discharge into the NCWSC System. 
Table 2. Distribution of Industries and treatment of effluents.

\begin{tabular}{ccc}
\hline No. & Item & Quantity \\
\hline 1. & Total no. of industries in Kenya & 4650 \\
2. & Total no. of industries in Nairobi & 2625 \\
3. & No. of industries not discharging into NCWSC System & 2025 \\
4. & No. of industries licensed by NCWSC & 1519 \\
5. & No. of industries discharging into NCWSC System & 600 \\
\hline
\end{tabular}

Source: National Bureau of Statistics and Nairobi City Water and Sewerage Company.

\section{Industries Emit Effluent Waste}

In a study conducted by the Otsieno Namwaya Mathews in his paper Industrial Discharge in Nairobi: An analysis of Regulatory Environment, Quality of Discharge and Media Coverage 2004, the study further sought the views of those who reside near industries in Nairobi whether, to the best of their knowledge, industries actually discharge effluent to the environment and the rivers near them. For some reason, most residential areas near industries in Nairobi are near rivers, all of which have been polluted by discharges from industries. The residents felt very strongly that industries discharged waste effluent into their neighbourhood, with (76\%) of the respondents saying so and just (12\%) saying otherwise.

Only (12\%) of the respondents said they were not aware of anything of the sort. It was evident that even those who said industries did not discharge effluent into the neighbourhood said so only because they had not paid keen attention to the matter since, as illustrated elsewhere in this study, they would later attribute some of the water problems in the rivers to discharges from industries. This makes the problem of effluent discharges from industries one of the biggest challenges Nairobi residents could be facing, albeit with little attention paid by the relevant authorities.

In Otsieno's study, the respondents who reside near industries, out of which (76\%) felt that the industries emit effluent to the environment, were willing to even give names of some of the industries that discharge their effluent to the neighbourhood. They included Manji Food Industries, Kartasi Industries, Cosmos, Raiply, Galsheet, Mareba, RAC Ceramic, Kalu Works, BOC, Bamburi Cement, Longhorn, KCC Ltd, East Africa Packaging Industries, R.H. Devani, Smikline, Tetra Pak, Spinners and Spinners, Blow Plast and Beechams. Even though mentioned randomly by the residents, these are exactly the same industries they cited as being situated close to residential areas. This could be taken to mean that, despite the regulatory authorities not keeping exhaustive records of discharges from industries, and despite the fact that the names dropped by residents are randomly cited and not exhaustive, it is likely that all industries near residential areas discharge their effluent in the neighbourhoods.

The residents were also able to directly link some ailments to the discharges 
from industries. In this regard, some of the highlighted effects, health or otherwise, of the effluent wastes included wounds by those who they said had come into contact with the effluent discharge from industries. The study indeed found that those residents who for some reason came into contact with the discharge from industries ended up with scars on various parts of their bodies, something that clearly shows that the discharges are untreated.

Yet, the respondents said they had neither themselves reported such cases to the authorities nor have they ever heard of a case in which any resident complained to the authorities about the effluent discharge and the attendant health effects. Such reluctance of the residents to complain or report cases of hazards from effluent discharges have been found by this study to be attributable to the following four reasons, mainly derived from responses by the respondents in this study: Majority of the respondents $37 \%$ said they no longer care about this kind or any other form of pollution of the environment because of fear of possible victimization by some of the law enforcement officials who they say have rather close relationship with the polluting industries. They could however not give any specific examples of those who have previously attempted to report and have been victimized, although they talked generally of resultant hostility from the management of the industries when reported upon.

The second reason cited by an equal proportion of respondents from the said study $37 \%$ is lack of support from the companies. The respondents indicated that, even when informed of the health hazards their discharges are causing the residents, the industries don't attempt to even find out what could have happened and whether there is anything wrong with their discharges. Instead, they resort to threatening the complainants and the victims. But the third group of respondents $16 \%$ held the view that it was upon the industries concerned to understand what their responsibility is with regard to the effluent discharge and therefore they should not wait for the residents to file complaints. It would appear that this apparent don't care attitude from a section of the public is a result of both frustrations due to lack of action by the concerned authorities and also due to lack of knowledge of the civic duty a member of public may have towards environmental sanitation.

But the responses from the fourth group, $10 \%$ appears to be an apparent indictment on the regulatory bodies and the extent of law enforcement. The residents indicated that they did not see the need to complain about effluent discharge since, even in the few cases where some people have bothered to file complaints, there still was little help from the concerned authorities. The respondents felt that the officers from NEMA have been compromised by the rogue industries and are therefore incapable of taking the right actions.

\section{Do Industries Treat Their Waste?}

Some of the challenges that are encountered when dealing with or managing effluent waste in Nairobi as identified by the study through desktop reviews in- 
cluded corruption within the regulatory agencies such as NEMA-Kenya, whose staff residents say have been compromised by the polluting industries and therefore lack the capacity to enforce the law. The other challenge was that it was difficult to monitor effluent discharge by steel industries and hence it is difficult to control the industries.

The other challenge cited in various studies and on NEMA's website was Nairobi's overstretched and poorly maintained sewerage system that regularly bursts, blocks and overflows during rainy seasons. The other challenge identified was the expanding informal settlements around industries in Nairobi, something that has made it difficult to design manageable sewer lines. The last challenge was the issue of poor infrastructure and the lack of skills and technological advancement to treat some types of wastes.

The industries according to NEMA reports could not easily provide the daily, monthly and yearly volumes of effluent waste generated in Nairobi, arguing that they were not directly involved in the effluent waste management. The industries felt that the laws, regulations and policies are not being enforced, something they blame on the oversight authorities, which they say are not keen on enforcing the laws and regulations. Some industries attributed this to lack of adequate staff, corruption and interference with the work of the oversight bodies by external forces.

Some of the measures suggested by different desktop review studies and articles as necessary in order to improve effluent waste management in Nairobi include stronger policy, regulatory and institutional framework; sensitizing the public on effluent waste and its health implications; instituting some changes within NEMA-Kenya, including what the respondents said was the need for a culture change in NEMA; strengthening NEMA-Kenya in terms of work force and capacity to enforce law and, finally, improvement of infrastructure, monitoring and surveillance as well as incorporation of media as a tool for public awareness.

\section{Summary of the Study}

The overall objective of this study was to establish the effects of steel industrial effluent on Nairobi metropolitan water pollution and its impact to the society. To achieve this, the study used a case study of Nairobi River on assessing whether there exist water pollution and the possible negative externalities accruing to the community living along the river and consuming the water. Specifically, the study sought to identify the various types of wastes produced by the factory, assess how the waste generated is managed and disposed; examine the effects of effluent discharge on Nairobi River and finally propose the mitigation measures that can be put in place to help curb the impacts of the steel factory effluent discharged into the river.

Secondary data was used in the analysis. Secondary data was collected through documentation review of relevant documents such as reports, newsletters and 
journals on effluent management and the results were presented in the form of tables and graphs.

Findings indicate that there are four categories of waste generated. They include solid waste during processing of steel products, liquid waste from the major and minor cleaning processes in the factory during steel processing and footbath chemicals as well as thermal wastes emanating from various heat losses that occur. Majority of respondents (76\%) indicated that industrial effluents had contaminated the Nairobi River. It was found that waste management in place was not effective enough leading to air and soil pollution. Other causes of pollution were found out to emanate from gasses contamination to the air and chemicals used during the steel processing process. These effluents found their way to the river through illegal dumping of untreated wastages by the steel processing factories, rain and erosion from the firms. With contaminated river water, $11 \%$ and $10 \%$ of the community reported to have suffered from water related illness including cholera and typhoid respectively.

A number of factors determined effect of pollution and contamination among the communities around the factory. Those living near the river especially in a half a kilometre radius and depending on the river water for drinking were the most affected by the pollution as compared to those within one-kilometre radius. Those reported to be living in a radius of two kilometres were not affected at all. Similarly, the longer the time one had stayed within and consumed the river the more likely he was to be affected by the contamination.

From the secondary data analysed, it was discovered that despite the existence and use of various water treatment mechanisms to help mitigate the effects, the data found out more than a half of the resident used untreated river water and they were the most affected by the illness. The most common water treatment mechanisms including sieving, boiling and using home treatment methods like chlorinating and use of water guard were found not to be fully reliable in mitigating against these effects since a number of infections were still reported even after having applied one or more of these mechanisms. This is called for more interventions lest the community continues suffering from these contaminations.

\section{Conclusion}

From the findings, it was revealed that steel processing plants produce solid, liquid and thermal wastes. Solid wastes are mainly steel metal by products generated from offloading bay, withering, processing, firing, sorting and packaging of steel products. Liquid waste is generated majorly from the cleaning processes in the factory during steel processing. Thermal wastes in the steel processing come from various heat losses that occur. These include loss of heat due to dry flue gas, loss of heat due to hydrogen, heat loss due to moisture in air, heat loss due to moisture in fuel and losses due to radiation. The untreated solid and liquid wastes are then dumped in the river through unlicensed waste emission pipes 
thus causing water pollution.

The findings indicated that most steel processing factories dump their untreated wastes in Nairobi River and have faulted to meeting government regulations either due to lack of proper waste management with the organization and also due to high costs that are imposed when treating the effluent discharge. Dumping their waste into the river therefore has been considered as the easiest way to release these dangerous effluents. Flaunting of waste management regulations has been the order due to corruption and lack of strict supervision from the environmental regulators.

The findings indicated that there were no proper waste management systems put in place by the steel processing factories. With these effluents finding their way to water bodies, they have a great deal of influence on the pollution by altering the physical, chemical and biological nature of the receiving water body and in this case Nairobi River. The respondents believed that waste from the steel factories causes both air and water pollution. Most of the respondents were aware that the waste from the factory polluted the environment while others believed that this pollution had a negative impact on the environment thus causing diseases. $12 \%$ of the respondents indicated that pollution causes diseases although the results indicated that they were not aware of any incidence of soil pollution causing diseases.

The findings indicted that due to water contamination the surrounding communities are vulnerable to various diseases and illnesses. It was revealed that a section of the community members living around the factory and depending on the Nairobi River for water confirmed that the water they use is contaminated as a result of factory wastes/discharge and some of the community use untreated water and so there existed a health risk to them. It was revealed that some of the community who use the untreated water were at least once in their lives affected by typhoid. The findings also indicated that sieving, home treatment practices and boiling are not $100 \%$ effective since at least one or two cases of infections still occurred. However, generally, there are few cases of infections like typhoid and cholera.

From the community's perspective on waste management, the secondary data revealed that there is need of treating waste before discharging. The results indicated that there is need for creating awareness among the water users dominated, use of piped water, tree planting and avoiding excessive chemical use in steel processing activities. Besides the preceding mitigation measures proposed by the affected, those who had never been affected in any way proposed use of piped water.

\section{Recommendations}

From the findings the paper recommends what ought to be done starting from the local affected communities, the factory management and finally the government as follows: 
From the result, Steel processing Factories produces solid, liquid and thermal wastes and gaseous pollutants. Solid wastes which are mainly generated from offloading bay, withering, processing, firing, sorting and packaging of steel products. The steel processing factory management ought to control this pollution and contamination through ensuring that pollution from these sources is treated before it is released to the environment. Liquid waste is generated which is generated from the cleaning processes in the factory during steel processing need to be treated as well. Thermal wastes which come from various heat losses that occur need to be cooled before being discharged to the river system. Gaseous pollutants need to be controlled to avoid it escape to the atmosphere. Water pollution coming from emissions from the factory, factory management ought to treat water before discharging it through the proper channels of the Nairobi Sewerage system. Environmental officers and the public health officers need to train the community and the residents around the area on proper waste disposal so as to avoid activities like dumping and bathing in the river. Learners in learning institutions can also be taught issues on environmental pollution control.

From the results, there were no proper waste management systems put in place by the factory, therefore in this regard, the steel processing factory managerial need to adopt proper waste management system to avoid such water pollution, they also need to have a created wetlands that can be used for waste water treatment before getting into the river system, the ministry of environment and more specifically the NEMA, Kenya is to ensure that environmental protection is strictly followed so that environmental degradation such as that of water pollution is controlled or prevented. There is need to create awareness on such issues as environmental pollution, especially that of water pollution since majority of the respondents seemed not to be aware of it. This can be done by the public health officers and the ministry of environment so that the community is aware of the adverse effects of water pollution, causes of diseases such as typhoid, cholera among other water borne diseases and illness.

The findings indicted that due to water contamination the surrounding communities are vulnerable to various diseases and illnesses. The community ought to be synthesised on the possible disease and illness caused by contaminated water. There is need for the frequent water testing especially that of Nairobi River. Before the treated waste water is discharged, water officers are supposed to do water analysis on any heavy metals and other contaminants. This will ensure that the water in the river is free of any contamination. The community ought to be working closely with the water and public health officers so that they are all aware of the treatment practices that they need to adopt and types of water born infections (such as typhoid and cholera) that they affect them as a result of water pollution and also the made aware of the best water treatment practices such as boiling water before drinking, used of domestic disinfectants like use of water guards.

From the findings waste management and mitigation measures to water pol- 
lution and contamination, need to be strictly followed and even sensitised to the community especially those close to rivers as they mainly depend on such water source. The owners of the steel factories are supposed to be treating waste water before discharging it into any environment.

The government and especially the ministry of environment need to have a campaign on water pollution prevention and control so that everyone is aware of the occurrence. Tree planting is a major requirement by everybody so that it can help in waste water treatment. Using piped water that is treated also goes a long way in preventing the water borne diseases.

Most importantly environmental players should craft a health protection policy that focuses on the affected population. This policy may ensure that industries and other pollutants are compelled to promote and maintain the health needs of the surrounding population as well as establish clear compensation criteria for the affected.

\section{Areas for Further Study}

There is room for more research in this area especially assessing the relationship between effluence discharged, pollution and cancer. This may entail high level kind of research in the medical field involving complex laboratory tests and time series data on morbidity rates among the local communities.

\section{Conflicts of Interest}

The authors declare no conflicts of interest regarding the publication of this paper.

\section{References}

Adepetu, A. A., \& Ezianshi, A. (1998). Man-Environment Relationships. Competing Conflicting Philosophies and Paradigms. Journal of Environmental Sciences, 1, 1-9.

Budambula, N. L. M., \& Mwachiro, E. C. (2006). Metal Status of Nairobi River Waters and Their Bioaccumulation in Labeocylindricus. Water, Air, and Soil Pollution, 169, 275-291.

Catton and Dunlap $(1978,1980)$. Theories of Environmental Degradation and Ecological Reform. Chrone, 2016.

Cheng, E. (2011). Theories and Interpretations of Environmental Policy. https://www.e-ir.info/2011/07/06/theories-and-interpretations-of-environmental-polic $\mathrm{y}-2 /$

Creswell, J. W. (2003). Research Design: Qualitative, Quantitative, and Mixed Methods Approaches (2nd ed.). Sage.

Dara, S. S. (2002). Environmental Chemistry and Pollution Control (p. 402). Chad and Company Publishing House.

Erling, B. (2003). Environmental Protection in the Theory of Commons. Thailand, 11-14 July 2003.

Georsesu, R. (2013). Some Theories of Environmental Sustainability, Inna-Virginia Dragulanescu, Natalia.

Hardin, G. (1968). The Tragedy of the Commons. Science, 162, 1243-1248. 
https://doi.org/10.1126/science.162.3859.1243

Hasnas, J. (2009). Two Theories of Environment Regulation. Social Philosophy \& Policy, 26, 95-129. https://doi.org/10.1017/S0265052509090189

Hassan, H. M., \& Amadi, P. (2013). Industrial Waste Management with Application of RIAM Environmental Assessment: A Case Study on Tools of Industrial Wastes. Iranica Journal of Energy and Environment, 4, 142-149.

Kazungu, R. (2010). Improving Governance for Sustainable Waste Management in Nairobi. The 46th ISOCARP Congress, Nairobi, 19-23 September 2010, 1-8. http://www.isocarp.net/Data/case studies/1799.pdf

Kinchella, C. E., \& Hyland, M. C. (1993). Water Pollution. In C. E. Kinchella, \& M. C. Hyland (Eds.), Environmental Science: Living within the System of Nature (pp. 337-380). Pearson College Div.

Kinuthia, G. K., Ngure, V., Beti, D., Lugalia, R., Wangila, A., \& Kamau, L. (2020). Levels of Heavy Metals in Wastewater and Soil Samples from Open Drainage Channels in Nairobi, Kenya, Community Health Implication. Daystar University Laikipia University, KEMRI, July 2020. https://doi.org/10.1038/s41598-020-65359-5

Lan, W. U., Gang, G. E., \& Jinbao, W. A. N. (2009). Biodegradation of Oil Wastewater by Free and Immobilized Yarrowia Lipolytica W29. Journal of Environmental Sciences, 21, 237. https://doi.org/10.1016/S1001-0742(08)62257-3

McMichael, A. J., Powles, J. W., Butler, C. D., \& Uauy, R. (2007). Food, Livestock Production, Energy, Climate Change, and Health. The Lancet, 370, 1253-1263. https://doi.org/10.1016/S0140-6736(07)61256-2

Monyoncho, G. O. (2013). Solid Waste Management in Urban Areas Kenya: A Case Study of Lamu Town. Doctoral Dissertation, University of Nairobi.

Moriarity, F. (1990). Ectotoxicity. In A Study of Pollutants in Ecosystems (2nd ed., pp. 134-146). Academic Press.

Mugenda \& Mugenda (2003). Business Research Methods. Salemi Publications.

Musembi, R., Wafula, H., Juma, A., Sakwa, T., Kitui, M., \& Araoz, R. (2015). Role of Cl on Diffusion of $\mathrm{Cu}$ in $\mathrm{In}_{2} \mathrm{~S}_{3}$ Layers Prepared by Ion Layer Gas Reaction Method. Coatings, 5, 54-62. https://doi.org/10.3390/coatings5010054

Muthaka, D. I., Kimani, D. N., Mwaura, S., \& Manda, D. K. (2004). A Review of the Regulatory Framework for Private Healthcare Services in Kenya. Kenya Institute for Public Policy Research and Analysis.

Mwangi (1988). Heavy Metal Pollution in Sediments, Water and Flora along Thika River. UON, June 2018.

Ndwaru, W. (1994). Findings of the Pollution Survey and the Need for Pollution Control. Proceedings of the Workshop on Abatement of Pollution in Nairobi Rivers, Nairobi, 15-17 August 2006, 15-18.

Njenga, H. N., Oyake, L., \& Kamau, G. N. (2009). Effects of Nairobi Industrial Area's Effluents on Levels of Ngong River Pollution. International Journal of BioChemiPhysics, $17,1-12$.

Ojanji, W. (2014). The Role Played by Print Media in Law Enactment: A Case Study of the Biosafety Law in Kenya. Doctoral Dissertation, University of Nairobi.

Okello, N., Beevers, L., Douven, W., \& Leentvaar, J. (2009). The Doing and Un-Doing of Public Participation during Environmental Impact Assessments in Kenya. Impact Assessment and Project Appraisal, 27, 217-226.

https://doi.org/10.3152/146155109X465940 
Okoth, P. F., \& Otieno, P. (2001). Pollution Assessment Report of the Nairobi River Basin, $U N E P$ (p. 106). AWN.

Omoto, E. (2006). A Study of Nairobi Wastewater Treatment Efficiency and Effluent Quality for Safe Discharge and Possible Beneficial Uses. MSc Thesis, The University of Nairobi.

Otieno, F. A. O. (1995). Role of Industries in Sustaining Water Quality. 21st WEDC Conference, Sustainability of Water and Sanitation Systems, Kampala, Uganda, 4-8 September 1995, 144-147.

Otsieno Namwaya Mathews (2004). Industrial Discharge in Nairobi: An Analysis of Regulatory Environment, Quality of Discharge and Media Coverage. Kenyatta University.

Sanchez, F. R., \& Bosch, C. O. (2005). Effluent Analysis in Analytical Chemistry: An Overview. Analytical and Bioanalytical Chemistry, 382, 978-991.

Scudine (1998). Encyclopaedia of Occupational Health and Safety(4th Ed.). ILO.

The National Council for Law Reporting (1986). Prohibition against Dangerous Handling and Disposal of Wastes. In Environmental Management and Co-Ordination Act (Chapter 387). The National Council for Law Reporting.

The National Council for Law Reporting (1999). Prohibition against Dangerous Handling and Disposal of Wastes. In Environmental Management and Co-Ordination Act (Revised ed., Chapter 387). The National Council for Law Reporting.

The National Council for Law Reporting (2015). National Solid Waste Management Strategy.

Virginia Dragulanescu \& Natalia Dragulanescu (2013). Some Theories of Environmental Sustainability. Romanian Statistical Review, 61, 14-23.

Wangombe, D. K. (2013). The Quality of Corporate Environmental Reporting in Kenya. International Journal of Economics and Accounting, 4, 327-349.

https://doi.org/10.1504/IJEA.2013.059884 


\section{Appendix 1: Ndandora Damping Site}

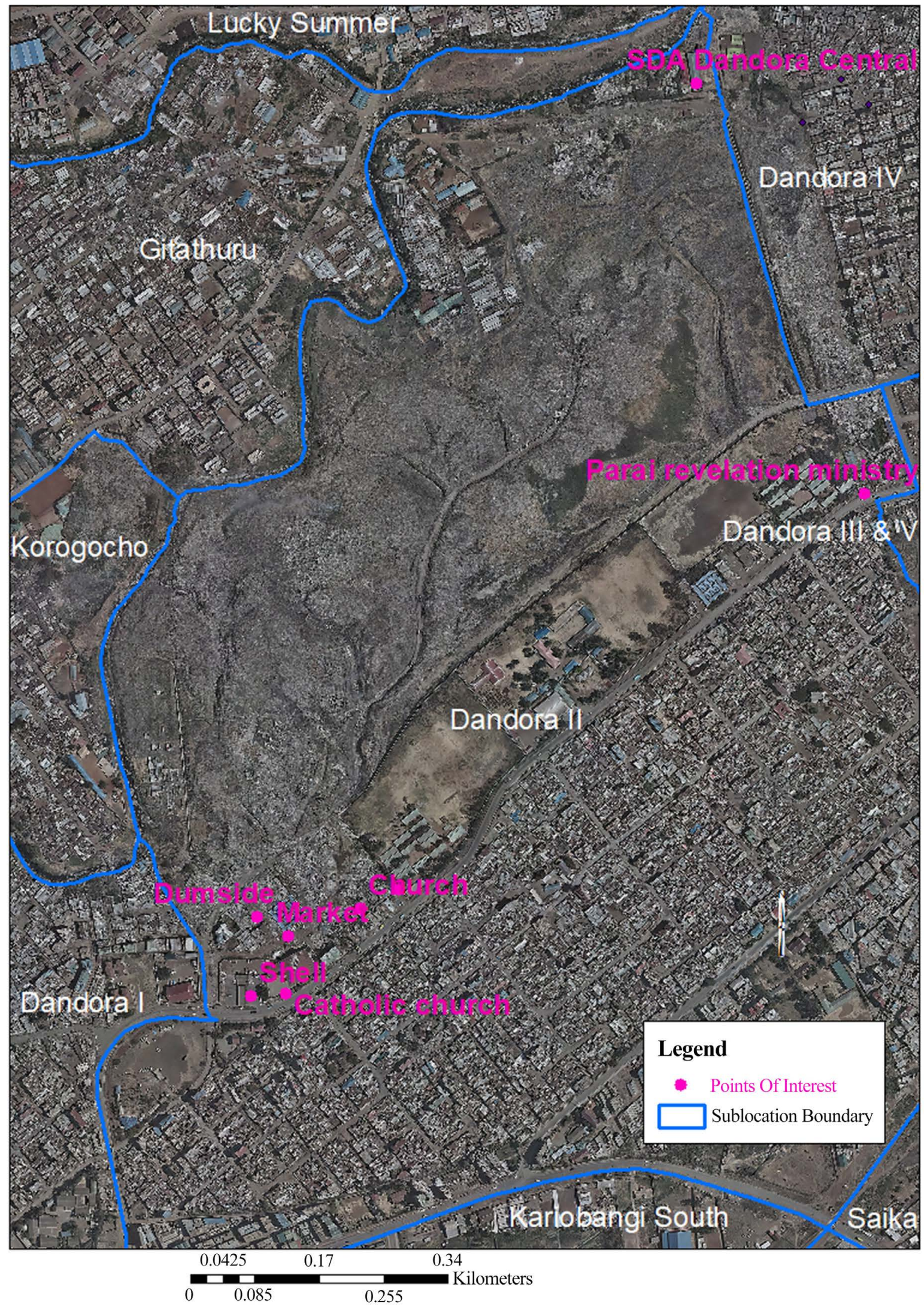




\section{Appendix 2: Ruai Sterilization Plant}

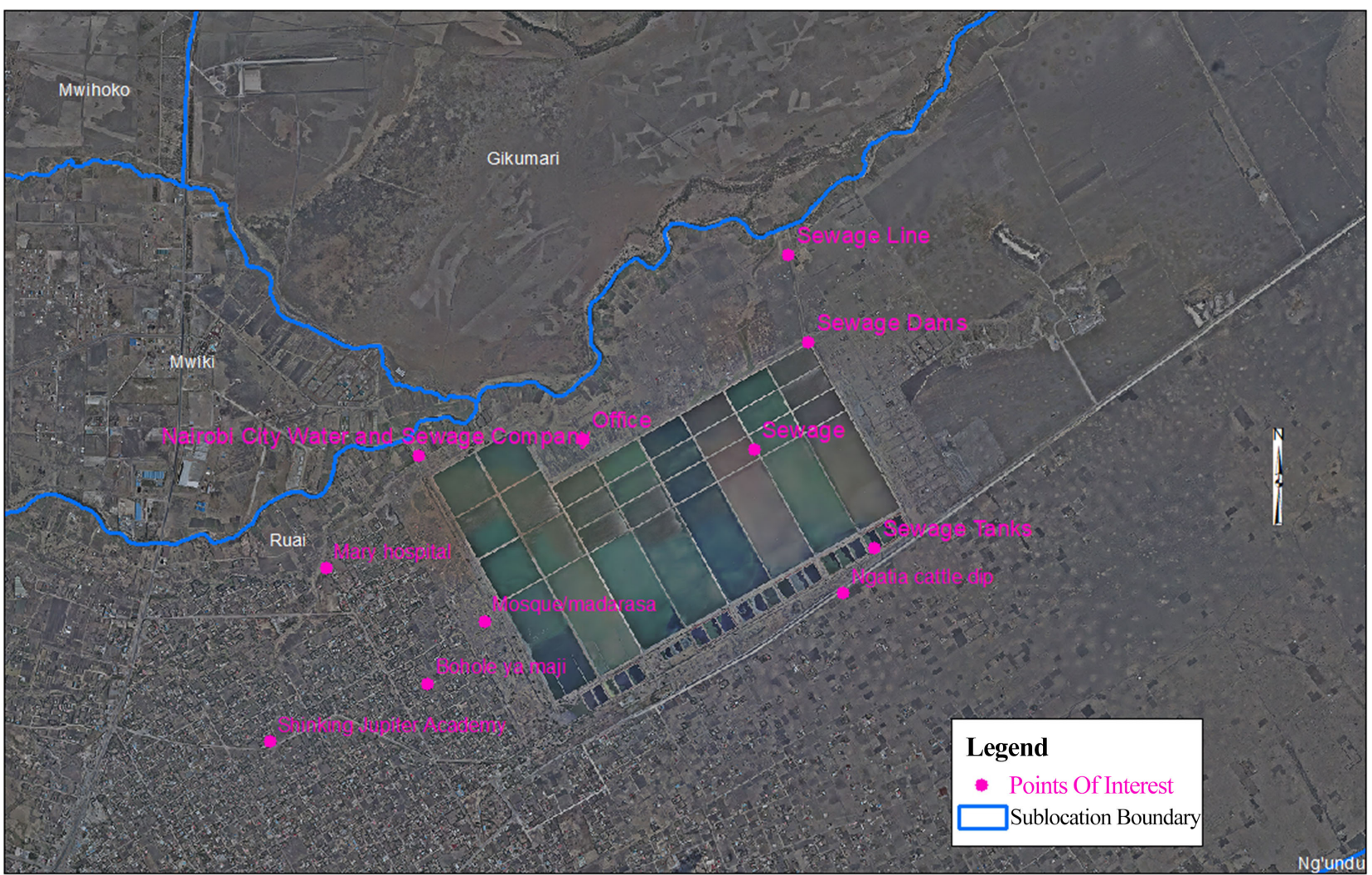

$\begin{array}{llll}1 & 0.5 & 0 & \text { Kilometers }\end{array}$ 


\section{Appendix 3: Location of Industries}

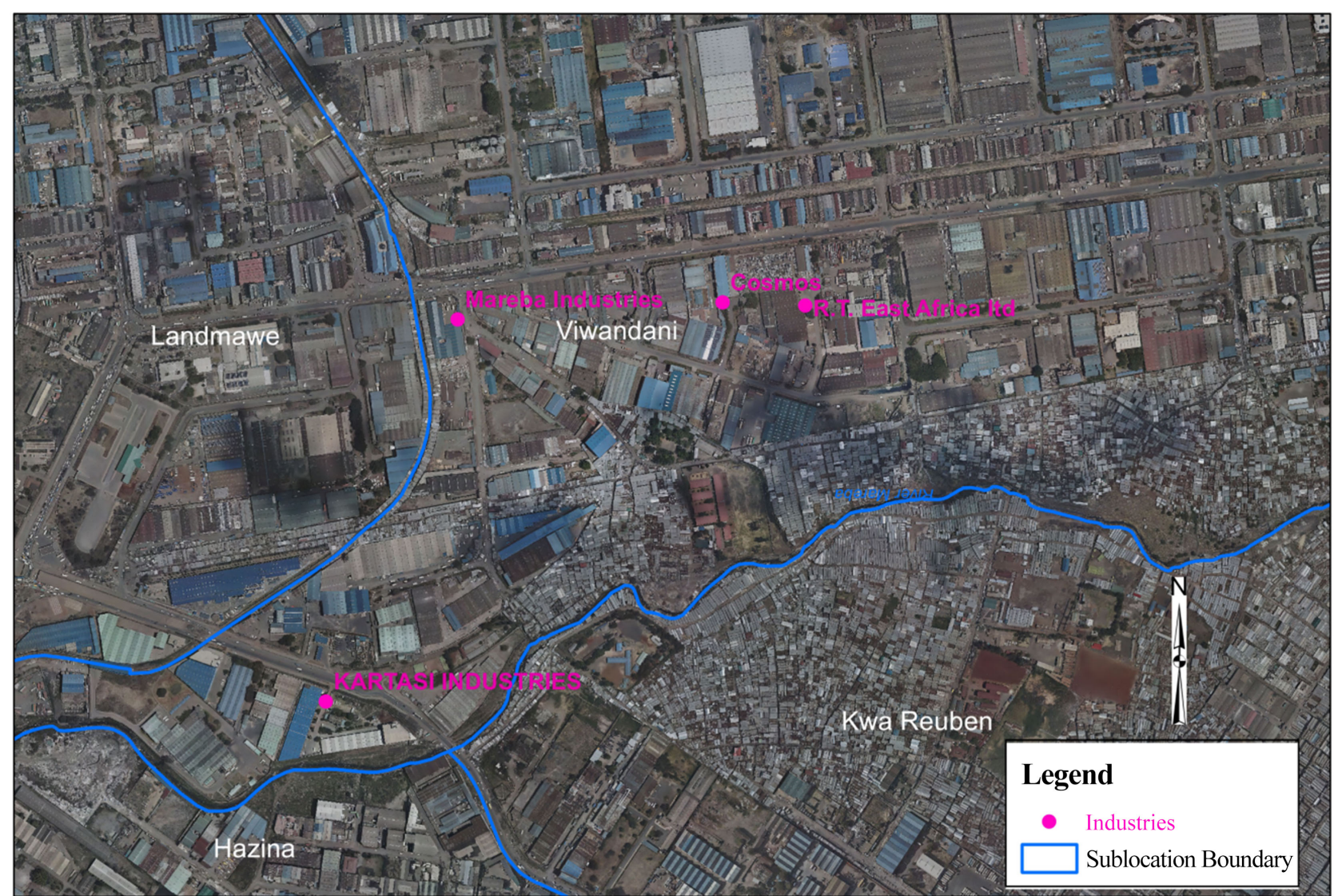

$\begin{array}{llll}0.25 & 0.125 & 0 & 0.25 \text { Kilometers }\end{array}$ 